\title{
The prescription patterns and safety profiles of oral non-steroidal anti-inflammatory drugs in China: an 8-year real-life analysis
}

\author{
Qingjun Meng ${ }^{1}$, Zhen Zhang ${ }^{1}$, Faxin $\mathrm{Li}^{2}$, Jinguang $\mathrm{Li}^{3}$, Na Wang ${ }^{4}$, Zhiwei Guo ${ }^{5}$, Jinqiang Wang ${ }^{5}$, \\ Xiaoran $\mathrm{Ye}^{6}, \mathrm{Yi} \mathrm{Li}^{5}$ \\ ${ }^{1}$ Department of Orthopedics, Third Hospital of Jinan, Jinan, China; ${ }^{2}$ Department of Rheumatism and Immunology, Jinan Central Hospital, Jinan, \\ China; ${ }^{3}$ Department of Orthopedics, Zhangqiu District People's Hospital, Jinan, China; ${ }^{4}$ Department of Rheumatism and Immunology, Zhangqiu

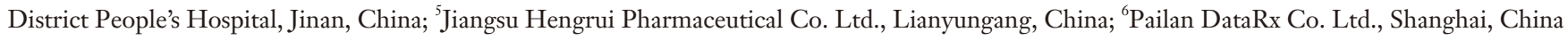 \\ Contributions: (I) Conception and design: Y Li, Q Meng; (II) Administrative support: Y Li, Z Guo, J Wang; (III) Provision of study materials or \\ patients: F Li, J Li, N Wang; (IV) Collection and assembly of data: X Ye; (V) Data analysis and interpretation: X Ye; (VI) Manuscript writing: All \\ authors; (VII) Final approval of manuscript: All authors. \\ Correspondence to: Yi Li. Jiangsu Hengrui Pharmaceutical Co. Ltd., Lianyungang, China. Email: liyi@hrs.com.cn.
}

Background: This study aimed to evaluate the prescription patterns and safety profiles of oral nonsteroidal anti-inflammatory drugs (NSAIDs) in three Chinese hospitals.

Methods: The study analyzed the data of 50,732 patients who were prescribed oral NSAIDs from July 1, 2012 to August 31, 2019. The characteristics of these patients, the prescription patterns of NSAIDs, and the drug-related safety profiles were evaluated.

Results: Oral NSAIDs were prescribed to patients of all ages. Of the patients, $81.88 \%$ were prescribed NSAIDs on only one occasion, and $91.64 \%$ were prescribed one type of NSAID only. The combination of different NSAIDs accounted for 2,360 person-times. Orthopedic departments most commonly used selective cyclo-oxygenase-2 (COX-2) inhibitors, while emergency departments most commonly used traditional NSAIDs. The incidences of gastrointestinal (GI) complications, cardiovascular (CV) events, and newonset hypertension were lower in patients treated with selective COX-2 inhibitors than those treated with traditional NSAIDs and NSAID combinations $(\mathrm{P}<0.05)$. In relation to selective COX-2 inhibitors, incidences of new-onset hypertension were lower in patients treated with imrecoxib than those treated with other types of selective COX-2 inhibitors ( $\mathrm{P}=0.0102)$.

Conclusions: In respect of the at-risk patients (i.e., those with related disease, such as GI complications, $\mathrm{CV}$ events or other risks), the patterns with which oral NSAIDs were prescribed was not standardized. In terms of adverse effects, selective COX-2 inhibitors represent a better choice than traditional NSAIDs and NSAID combinations.

Keywords: Oral non-steroidal anti-inflammatory drugs (oral NSAIDs); prescription patterns; safety profiles; selective cyclo-oxygenase-2 inhibitors (selective COX-2 inhibitors); traditional NSAIDs

Submitted Oct 30, 2020. Accepted for publication Dec 29, 2020.

doi: 10.21037/apm-20-2356

View this article at: http://dx.doi.org/10.21037/apm-20-2356

\section{Introduction}

Non-steroidal anti-inflammatory drugs (NSAIDs) are one of the most frequently used classes of medicines in the world, accounting for nearly $5 \%$ of all prescribed medications (1). An inhibitory effect of NSAIDs on cyclo- oxygenase (COX) activity is responsible for their antiinflammatory actions. COX is an enzyme essential for the synthesis of prostaglandins (PGs), such as $\mathrm{PGE}_{2}$, which have a strong capacity to induce inflammation. COX is expressed in cells in two distinct isoforms. COX-1 is present constitutively, while COX-2 is expressed primarily 
after an inflammatory insult. NSAIDs inhibit COX-2 at the site of inflammation, which produces therapeutic benefits, and $\mathrm{COX}-1$ in the gastric mucosa, which produces gastric damage (2). In recent years, a growing number of selective inhibitors of COX-2 have been developed.

NSAIDs are extensively used to treat acute or chronic arthritis, headaches, visceral pain, postoperative pain, and various musculoskeletal problems (3-6). There is extensive evidence that NSAIDs improve individuals' quality of life by relieving pain effectively, and reducing local and systemic inflammatory responses $(7,8)$. However, NSAIDs are also associated with a number of adverse effects, including hypertension, cardiovascular (CV) disease, kidney injury and gastrointestinal (GI) complications $(9,10)$. Additionally, research has shown that children and adolescents may have hypersensitivity reactions to NSAIDs $(11,12)$.

Some researches recommend that NSAIDs should be avoided in patients at high risk of related diseases $(10,13)$. However, due to the wide variety of NSAIDs available and the diversity of diseases to which they are applied, the side effects and the use of NSAIDs may not always be linked to one another. Thus, it is necessary to address the prescription mode adopted for and safety profiles of NSAIDs to fully understand the clinical application of NSAIDs.

The main objectives of this study were to: (I) summarize the characteristics of patients prescribed oral NSAIDs; (II) compare the clinical applications of NSAIDs across different departments and in the treatment of different diseases; and (III) examine the factors affecting NSAIDinduced adverse effects in China. We present the following article in accordance with the STROBE reporting checklist (available at http://dx.doi.org/10.21037/apm-20-2356).

\section{Methods}

\section{Participants}

The participants in this study comprised patients who were prescribed oral NSAIDs, including imrecoxib, celecoxib, etoricoxib, ibuprofen, diclofenac sodium, indomethacin, and acetaminophen, for the first time while being treated at the Third Hospital of Jinan, Jinan Central Hospital, and Zhangqiu District People's Hospital in Jinan, Shandong, China from July 1, 2012 to August 31, 2019 and for whom diagnostic information was available. All the aforementioned oral NSAIDs were considered in this study, as these NSAIDs are widely used and have been approved for marketing for at least nine years in China, and thus were deemed suitable for this 8-year analysis of hospital patients.

\section{Ethics}

This study conformed to the standards of the Declaration of Helsinki (as revised in 2013) and current ethical guidelines and was reviewed and approved by the Institutional Review Board of the Third People's Hospital of Jinan (No. 2020sy-005). The need for informed consent was waived by the Institutional Review Board.

\section{Prescription data used for the study}

The data analyzed in the study had been stored in the hospital information systems (HISs) of the three hospitals in accordance with the legal requirements and were governed by current applicable statutory provisions. Data about patients, including age, gender, marriage status, ethnicity, hospital admission route, hospital department admission, payment of treatment fee(s), prescription and diagnostic information, and other clinical procedures (e.g., surgery) at hospital admission (both before and after NSAID prescriptions), were collected.

\section{Study design}

This retrospective, observational and pharmacological study examined prescription information at three hospitals in Shandong, China from July 1, 2012 to August 31, 2019.

\section{Endpoints}

\section{Personal characteristics of patients prescribed oral NSAIDs}

Patients' baseline personal and clinical characteristics were analyzed. Patients were classified into one of the following three groups based on the NSAIDs that they had been prescribed: (I) patients prescribed selective COX-2 inhibitors (imrecoxib, celecoxib, or etoricoxib); (II) patients prescribed traditional NSAIDs (e.g., ibuprofen, diclofenac sodium, indometacin, or acetaminophen that inhibit COX1 and COX-2 non-selectively); and (III) patients prescribed a combination of NSAIDs (i.e., at least two types of NSAID during one hospital admission).

\section{Follow-up period}

The follow-up period was defined as the total number of days from the day a patient was first prescribed an NSAID 
or a combination of NSAIDs to the last day that medical records of that same patient could be retrieved from the HISs.

\section{Risk factors and the prescription of oral NSAIDs}

Participants' medical histories and concomitant medications were evaluated based on their diagnostic and prescription data. Adopting the approach of Szeto et al. (10), patients were defined as being at risk of GI complications if they possessed one or two of the following risk factors: (I) were aged $>65$; (II) had a previous history of an uncomplicated ulcer; (III) concurrently used aspirin (low or high doses), antiplatelet drugs, corticosteroids, or anticoagulants; and (IV) had a history of a previously complicated ulcer (especially, recent ulcers). Patients were defined as being at high risk of a CV event if they had a history of an ischemic vascular event (e.g., angina, myocardial infarction, stroke, transient ischemic attack, or intermittent claudication), or heart failure.

\section{Prescription patterns of oral NSAIDs}

To determine prescription patterns of NSAIDs, an analysis was undertaken of clinical department and diagnostic information relating to each prescription of an NSAID or a combination of NSAIDs to patients at admission, and each prescription of a proton pump inhibitor (PPI) to patients at risk of GI complications.

\section{Safety profiles of oral NSAIDs}

To examine the safety profiles of different types of NSAIDs, the data of patients who were prescribed only one type of NSAID and those prescribed at least two types of NSAID during one clinical admission were included in the study. These patients were then classified as falling into one of the following three groups: (I) patients prescribed selective COX-2 inhibitors; (II) patients prescribed traditional NSAIDs; and (III) patients prescribed a combination of NSAIDs. The occurrence of GI complications and CV events in at-risk and not-at-risk patients, and new-onset hypertension in patients after the use of NSAIDs was also analyzed.

\section{Subgroup analysis}

A subgroup analysis was undertaken of patients prescribed selective COX-2 inhibitors, including imrecoxib, celecoxib and etoricoxib, to determine the safety profiles of these drugs.

\section{Statistical analysis}

The distributions of age, follow-up period, frequency, and type of NSAID prescribed were expressed in terms of frequencies (\%) and medians [with interquartile ranges (IQRs)], while other parameters were expressed in terms of frequencies (\%). A Pearson Chi-square test or a Fisher's Exact test was used to explore the safety profiles of different NSAIDs. All the statistical analyses were conducted in $\mathrm{R}$ Version 3.3.3 (R Foundation for Statistical Computing, Vienna, Austria). A $\mathrm{P}<0.05$ was considered statistically significant.

\section{Results}

\section{Overall prescription of NSAIDs}

A total of 50,732 patients participated in the study from July 1, 2012 to August 31, 2019. Of the patients, 16,815, 33,460 and 457 patients were prescribed selective COX2 inhibitors, traditional NSAIDs, and at least two types of NSAIDs at baseline admission, respectively (see Table 1). The median age of patients was 44.4 years (with an IQR of 26.6 to 60.8). The results showed that patients treated with selective COX-2 inhibitors were older than those treated with traditional NSAIDs (52.7 vs. 35.7 years). Of the patients, $48.31 \%$ were male, and $51.10 \%$ were female (thus, the ratio of male to female patients was similar), and $77.54 \%$ of Han ethnicity $(77.54 \%)$. Of the patients, most $(82.44 \%)$ were prescribed NSAIDs by out-patient departments. In relation to the payment methods of medication fees, only $28.66 \%$ of patients were covered for NSAIDs by their medical insurance, and a majority of patients $(53.11 \%)$ were self-paying (i.e., had to cover the costs of the NSAIDs personally). The median followup period for all patients was 3 days (with an IQR of 1 to 15 ). Notably, the follow-up period was longer for patients prescribed traditional NSAIDs than those prescribed selective COX-2 inhibitors ( 1 vs. 4 days) at baseline admission. Over $80 \%$ of patients were prescribed NSAIDs only once, and less than $10 \%$ of patients used more than one type of NSAID. These results were similar across patients in both the selective COX-2 inhibitor and traditional NSAIDs groups. See Table S1 in relation to the combination patterns for patients who were prescribed at least two types of NSAID. In total, there were 2,360 person-times of NSAID combination prescriptions, and $98.05 \%$ of these were prescribed combinations of two types of NSAID. 
Table 1 Characteristics of patients

\begin{tabular}{|c|c|c|c|c|}
\hline Variable & Overall $(n=50,732)$ & $\begin{array}{c}\text { Selective Cox-2 } \\
\text { inhibitors }(n=16,815)\end{array}$ & $\begin{array}{l}\text { Traditional NSAIDs } \\
\qquad(n=33,460)\end{array}$ & $\begin{array}{l}\text { NSAIDs combination* } \\
\qquad(\mathrm{n}=457)\end{array}$ \\
\hline \multicolumn{5}{|l|}{ Age, years } \\
\hline $0-6$ & $2,183(4.3 \%)$ & $28(0.17 \%)$ & 2,155 (6.44\%) & $0(0 \%)$ \\
\hline $7-12$ & $2,135(4.21 \%)$ & $44(0.26 \%)$ & 2,087 (6.24\%) & $4(0.88 \%)$ \\
\hline $19-44$ & $18,523(36.51 \%)$ & $5,109(30.38 \%)$ & 13,315 (39.79\%) & $99(21.66 \%)$ \\
\hline $45-64$ & $15,144(29.85 \%)$ & $7,058(41.97 \%)$ & 7,921 (23.67\%) & $165(36.11 \%)$ \\
\hline$\geq 65$ & $9,660(19.04 \%)$ & $4,159(24.73 \%)$ & $5,320(15.9 \%)$ & $181(39.61 \%)$ \\
\hline Unknown & $301(0.59 \%)$ & $121(0.72 \%)$ & 177 (0.53\%) & $3(0.66 \%)$ \\
\hline \multicolumn{5}{|l|}{ Marriage } \\
\hline Single & 765 (1.51\%) & $16(0.10 \%)$ & $743(2.22 \%)$ & $6(1.31 \%)$ \\
\hline Married & $2,982(5.88 \%)$ & $232(1.38 \%)$ & $2,671(7.98 \%)$ & 79 (17.29\%) \\
\hline Divorced & $5(0.01 \%)$ & $0(0 \%)$ & $5(0.01 \%)$ & $0(0 \%)$ \\
\hline Widowed & $38(0.07 \%)$ & $4(0.02 \%)$ & $34(0.10 \%)$ & $0(0 \%)$ \\
\hline Unknown & 46,942 (92.53\%) & $16,563(98.50 \%)$ & 30,007 (89.68\%) & $372(81.40 \%)$ \\
\hline \multicolumn{5}{|l|}{ Hospital admission route } \\
\hline Out-patient department & 41,824 (82.44\%) & $14,175(84.3 \%)$ & $27,510(82.22 \%)$ & $139(30.42 \%)$ \\
\hline Emergency department & $2,087(4.11 \%)$ & $4(0.02 \%)$ & $2,083(6.23 \%)$ & $0(0 \%)$ \\
\hline In-patient department & 6,517 (12.85\%) & $2,552(15.18 \%)$ & $3,649(10.91 \%)$ & $316(69.15 \%)$ \\
\hline Unknown & $304(0.6 \%)$ & $84(0.5 \%)$ & $218(0.65 \%)$ & $2(0.44 \%)$ \\
\hline \multicolumn{5}{|l|}{ Payment method } \\
\hline Medical insurance & $14,539(28.66 \%)$ & $4,700(27.95 \%)$ & $9,578(28.63 \%)$ & $261(57.11 \%)$ \\
\hline Rural cooperative medical service & $834(1.64 \%)$ & $609(3.62 \%)$ & $186(0.56 \%)$ & $39(8.53 \%)$ \\
\hline Self-paying & 26,945 (53.11\%) & $10,867(64.63 \%)$ & $15,985(47.77 \%)$ & $93(20.35 \%)$ \\
\hline Public health service & $2,234(4.4 \%)$ & $324(1.93 \%)$ & $1,870(5.59 \%)$ & $40(8.75 \%)$ \\
\hline Others & $6,065(11.95 \%)$ & $211(1.25 \%)$ & $5,834(17.44 \%)$ & $20(4.38 \%)$ \\
\hline
\end{tabular}

Table 1 (continued) 
Table 1 (continued)

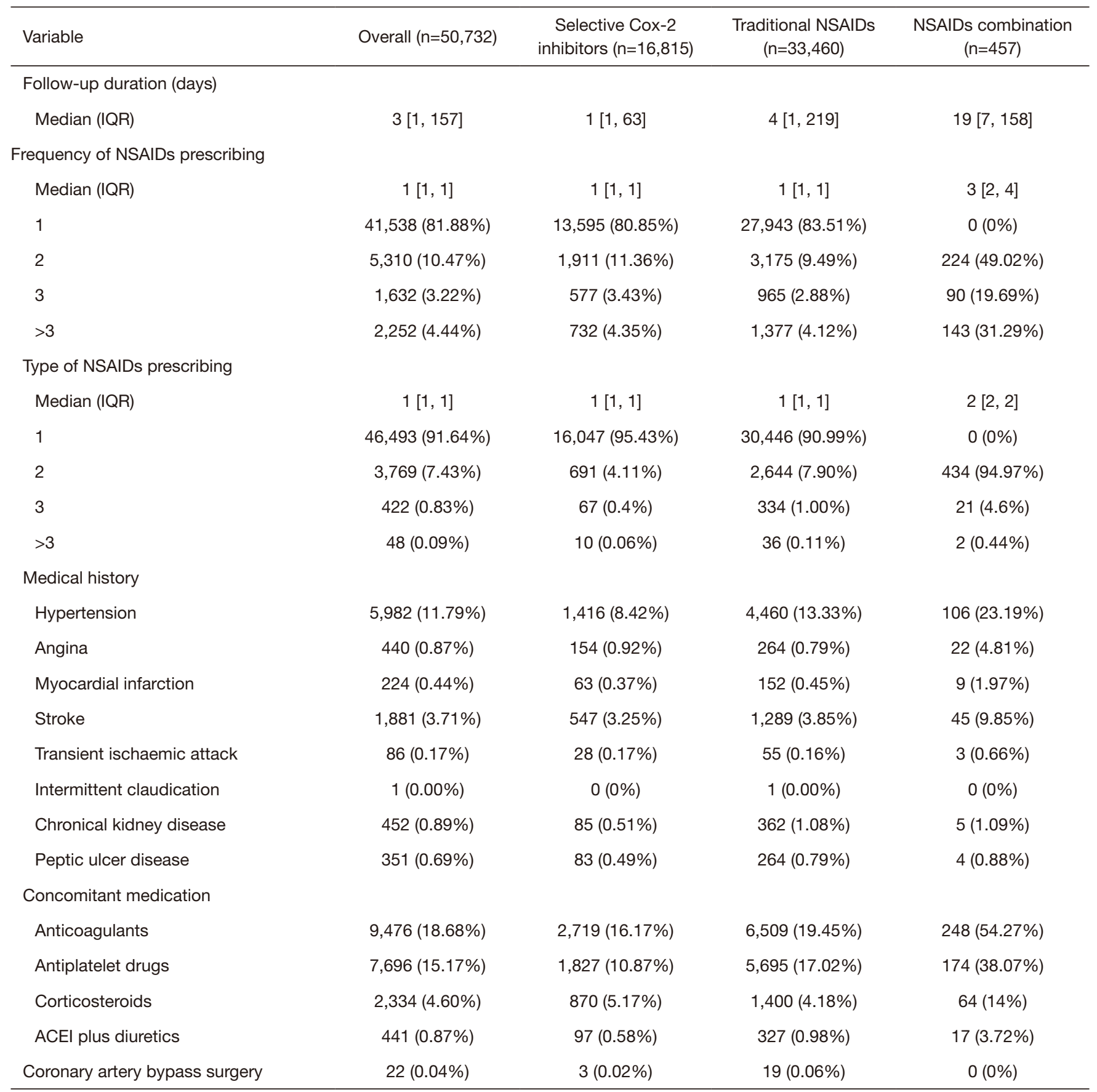

*, NSAIDs combination means patients who were prescribed with at least two kinds of NSAIDs at the first visit. NSAIDs, non-steroidal antiinflammatory drugs; COX, cyclooxygenase; NSAIDs, non-steroidal antiinflammatory drugs; IQR, interquartile range; ACEI, angiotensinconverting enzyme inhibitor.

\section{Prescription patterns of selective COX-2 inbibitors and traditional NSAIDs}

To determine the prescription patterns of NSAIDs, the distribution of physicians from different hospital departments, and the diagnosis information of patients prescribed NSAIDs were analyzed (see Figures 1 and 2, respectively). In relation to hospital departments, the 10 departments that prescribed selective COX-2 inhibitors 
A

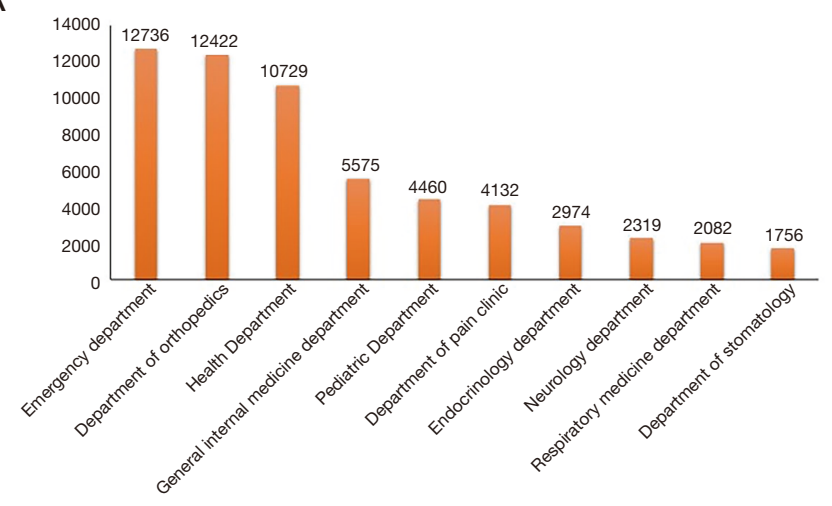

C

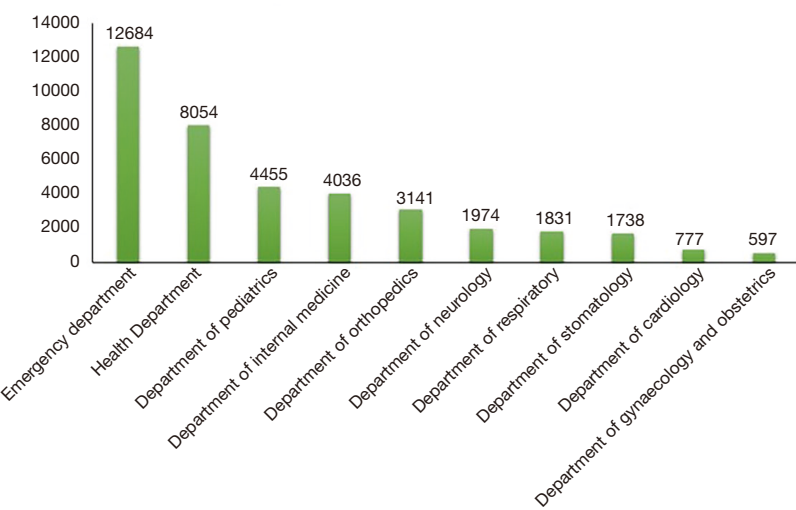

B

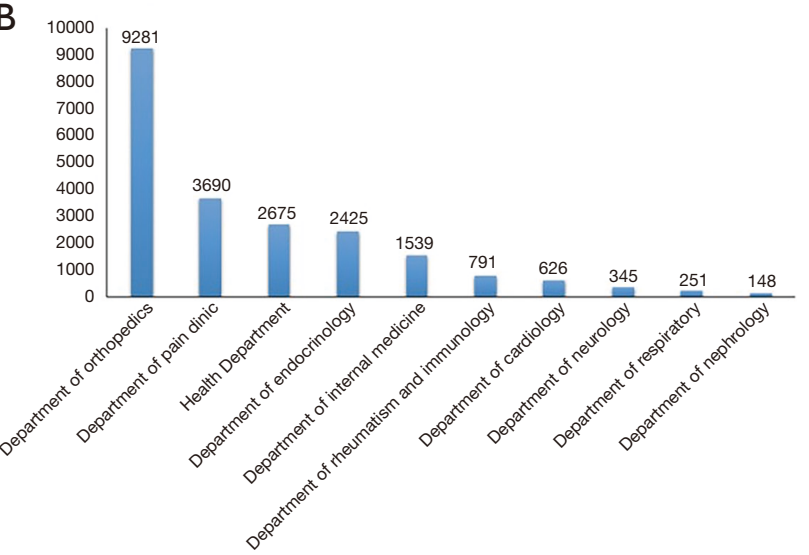

Figure 1 Pattern of NSAIDs prescription in different clinical departments (top-10, person-time). (A) All NSAIDs; (B) selective COX-2 inhibitors; (C) non-selective NSAIDs. NSAIDs, non-steroidal anti-inflammatory drugs; COX, cyclooxygenase.

the most frequently were the orthopedic, pain clinic, health, endocrinology, internal medicine, rheumatism and immunology, cardiology, neurology, respiratory, and nephrology departments (see Figure 1B). Conversely, the 10 departments that prescribed selective traditional NSAIDs the most frequently were the emergency, health, pediatrics, internal medicine, orthopedic, neurology, respiratory, stomatology, cardiology, gynecology, and obstetrics departments (see Figure 1C).

Further, the 10 most common diseases of patients prescribed both types of NSAIDs largely accorded with the results for the hospital departments. Patients with osteoarthritis, lower back pain, soft tissue injuries, rheumatoid arthritis, hypertension, bone fractures, diabetes mellitus, cervical spondylosis, coronary heart disease, and gout were most frequently prescribed selective COX2 inhibitors (see Figure 2B). Patients with fevers, upper respiratory infections, osteoarthritis, hypertension, diabetes mellitus, chronic ischemic heart disease, headaches, bronchitis, coronary heart disease, and soft tissue injuries were most frequently prescribed traditional NSAIDs (see Figure 2C).

\section{Risks of using NSAIDs}

This study also examined the proportion of at-risk patients who were prescribed NSAIDs. Of the patients in the present study, $14,473(28.53 \%)$ were at risk of GI complications, $2,465(4.86 \%)$ were at high risk of a CV event, 5,982 (11.79\%) had hypertension, and $452(0.89 \%)$ had a history of chronical kidney disease history. Further, 9,476 (18.68\%), $7,696(15.17 \%), 2,334(4.60 \%)$, and 441 (0.87\%) patients took concomitant anticoagulant medications, antiplatelet drugs, corticosteroids, and angiotensin-converting enzyme inhibitors (ACEI), respectively. Notably, patients were prescribed diuretics when NSAIDs were prescribed. In relation to the patients that underwent coronary artery bypass surgery, $22(0.04 \%)$ were prescribed NSAIDs 
A
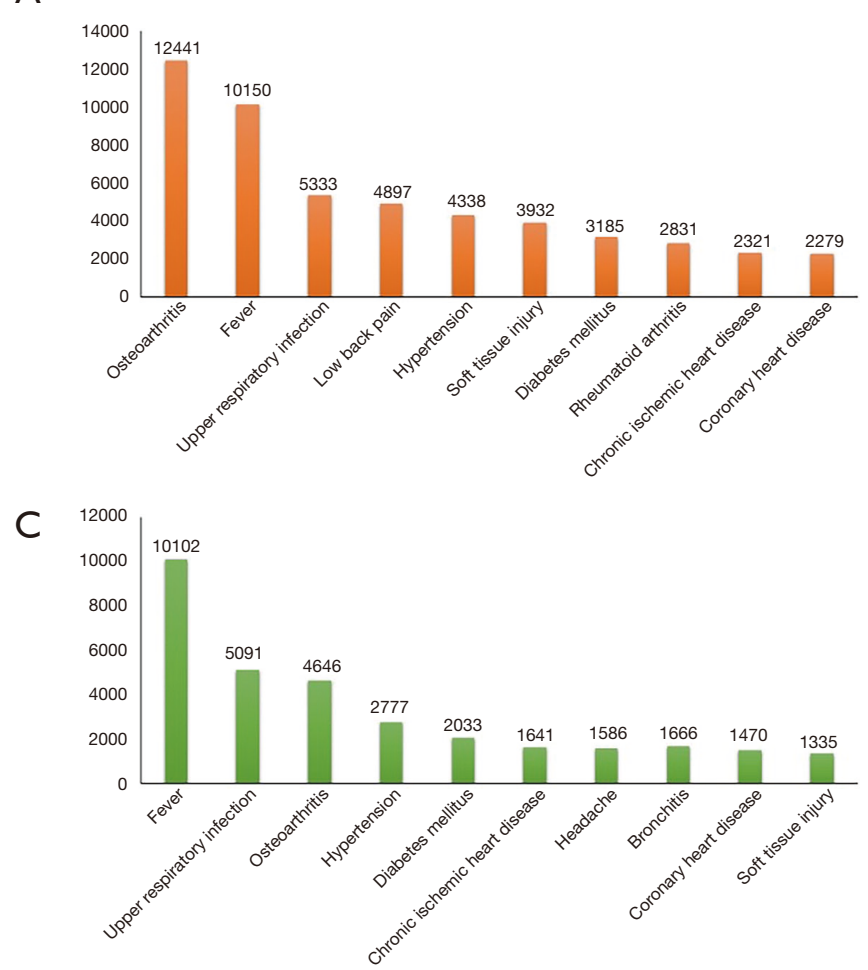

B 100000

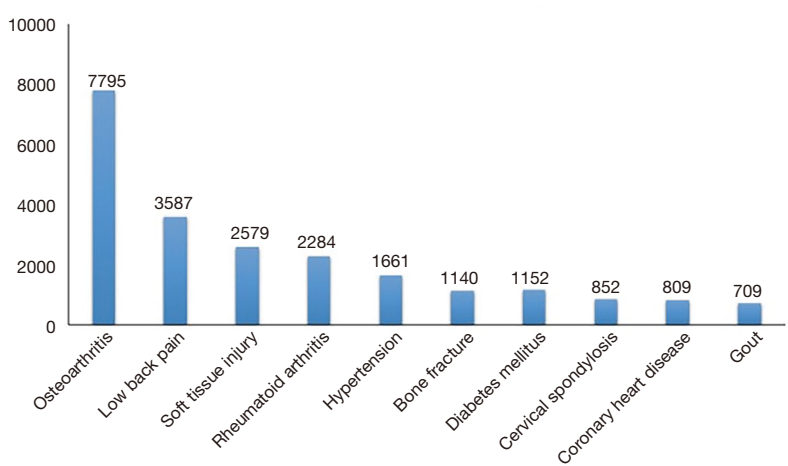

Figure 2 Pattern of NSAIDs prescription in different diseases (top-10, person-time). (A) All NSAIDs; (B) selective COX-2 inhibitors; (C) non-selective NSAIDs. NSAIDs, non-steroidal anti-inflammatory drugs; COX, cyclooxygenase.

Table 2 Prescription of PPIs in patients with or without gastrointestinal risk

\begin{tabular}{lccc}
\hline Risk classification & Overall & Selective COX-2 inhibitors & Traditional NSAIDs \\
\hline Overall & $6,422(12.66 \%)$ & $2,117(11.76 \%)$ & $4,476(13.04 \%)$ \\
Without gastrointestinal risk & $2,733(7.54 \%)$ & $517(4.41 \%)$ & $2,230(8.87 \%)$ \\
With gastrointestinal risk & $3,689(25.49 \%)$ & $1,600(25.52 \%)$ & $2,246(24.45 \%)$ \\
\hline
\end{tabular}

PPIs, proton pump inhibitors; COX, cyclooxygenase; NSAIDs, non-steroidal antiinflammatory drugs.

during the preoperative period (see Table 1). Notably, only $25.49 \%$ patients at risk of GI complications were prescribed NSAIDs and PPIs (see Table 2).

\section{Safety profiles of selective COX-2 inbibitors and traditional NSAIDs}

The occurrence of GI complications, CV events, and newonset hypertension was also analyzed. In relation to patients at risk of GI complications, the results showed that selective COX-2 inhibitors were safer than traditional NSAIDs and NSAID combinations among patients at risk or relative risk
(2.25\% vs. $4.67 \%$ vs. $6.70 \%, \mathrm{P}<0.0001 ; 0.35 \%$ vs. $0.92 \%$ vs. $2.70 \%, \mathrm{P}<0.0001$, respectively, Figure $3 A$ ). Further analysis suggested that selective COX-2 inhibitors induced less GI complications than traditional NSAIDs in both groups $(\mathrm{P}<0.0001$, Figure $3 A)$, and traditional NSAIDs were safer than NSAID combinations in the non-risk group $(\mathrm{P}=0.0301$, Figure 3 A). Similar results $(17.82 \%$ vs. $22.93 \%$ vs. $26.09 \%, \mathrm{P}=0.0175$, Figure $3 B$ ) were found for patients in the risk group in relation to $\mathrm{CV}$ events. Compared with traditional NSAIDs, selective COX-2 inhibitors did not increase the risk of $\mathrm{CV}$ events $(\mathrm{P}=0.0084$, Figure $3 B)$. In the non-risk group, selective COX-2 inhibitors were also 

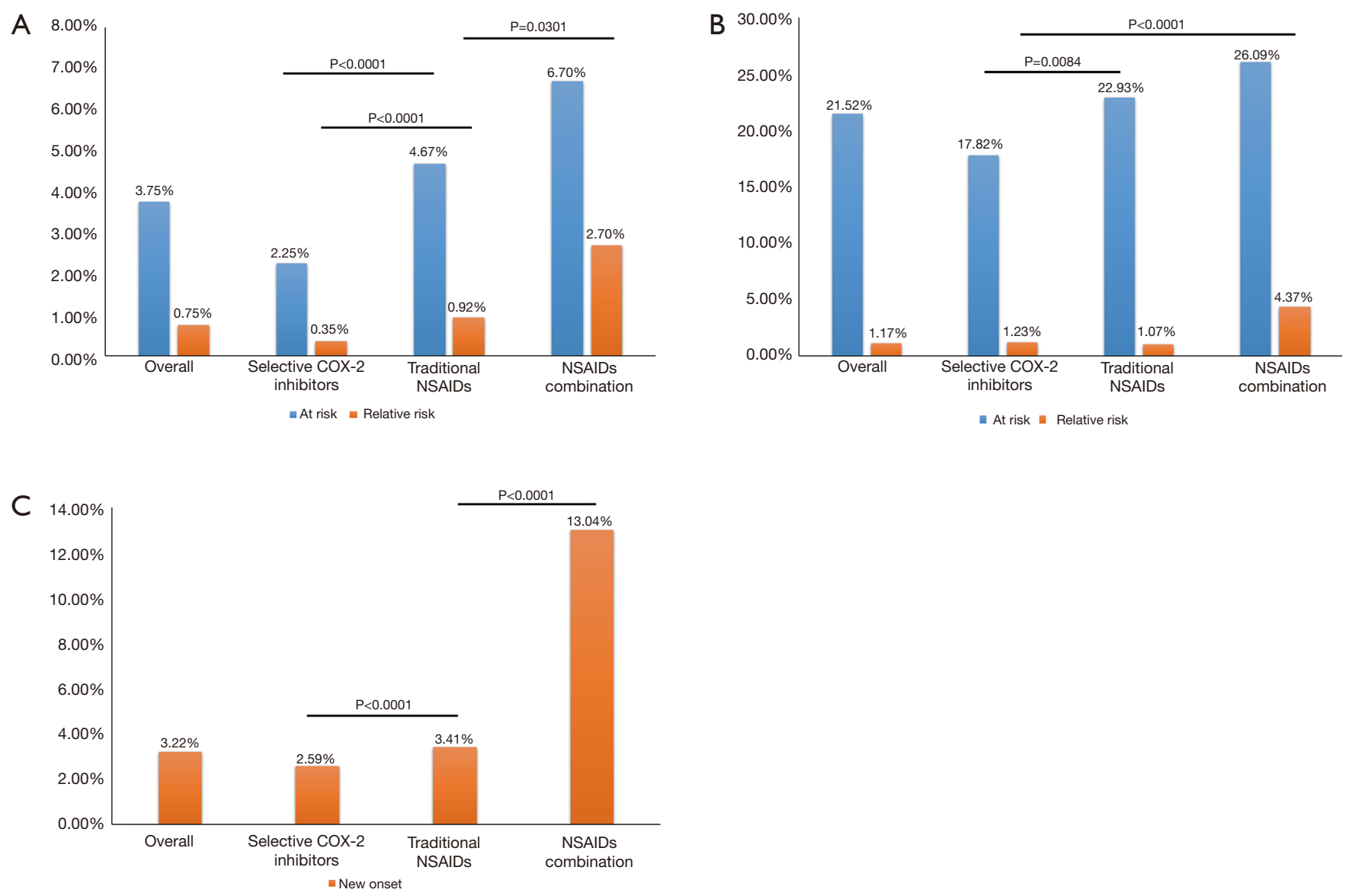

Figure 3 Occurrences of gastrointestinal complications, cardiovascular events and hypertension new-onset in patients at risk or relative risk after using different NSAIDs. (A) Gastrointestinal complications; (B) cardiovascular events; (C) hypertension new-onset. NSAIDs, nonsteroidal anti-inflammatory drugs.

found to be safer than NSAID combinations $(1.23 \%$ vs. $4.37 \%, \mathrm{P}<0.0001$, Figure $3 B$ ). In addition, the proportion of new-onset hypertension caused by selective COX2 inhibitors among patients was less than that caused by traditional NSAIDs and NSAID combinations $(2.59 \%$ vs. $3.41 \%$ vs. $13.04 \%, \mathrm{P}<0.0001$, Figure 3 C). Of these patients, the difference between selective COX-2 inhibitors and traditional NSAIDs was significant $(\mathrm{P}<0.0001$; Figure 3).

A subgroup analysis of the three selective COX2 inhibitors showed that while there was no significant difference among the three subgroups, the number of patients at risk of suffering from GI complications was relatively lower among patients treated with imrecoxib than patients treated with celecoxib or etoricoxib $(1.82 \%$ vs. $2.63 \%$ vs. $1.86 \%$, Figure $4 A$ ). In relation to patients who were not at risk of GI complications, the results of the three subgroups showed a statistically significant trend $(0.12 \%$ vs. $0.33 \%$ vs. $0.46 \%, \mathrm{P}=0.056$, Figure $4 A$ ). The incidence of GI complications caused by imrecoxib was lower than that caused by etoricoxib $(\mathrm{P}=0.0177$, Figure $4 A)$. In relation to $\mathrm{CV}$ events, the results for patients in the at-risk group were similar (11.63\% vs. $19.35 \%$ vs. $17.28 \%$, Figure $4 B)$. Conversely, the results for patients in the non-risk group revealed that imrecoxib was safer than celecoxib $(0.95 \%$ vs. $1.80 \%, \mathrm{P}=0.0016$, Figure $4 B$ ). Further, patients treated with celecoxib had a higher rate of new hypertension than those treated with imrecoxib (3.14\% vs. $2.32 \%, \mathrm{P}=0.0294$; Figure 4C).

\section{Discussion}

This study investigated recent prescription patterns of oral NSAIDs in real-world clinical settings using the databases of three Chinese hospitals. The results provided insights 
A

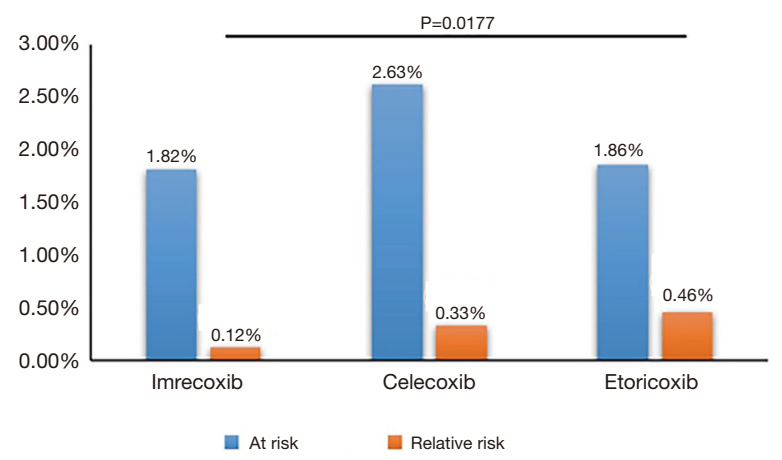

C

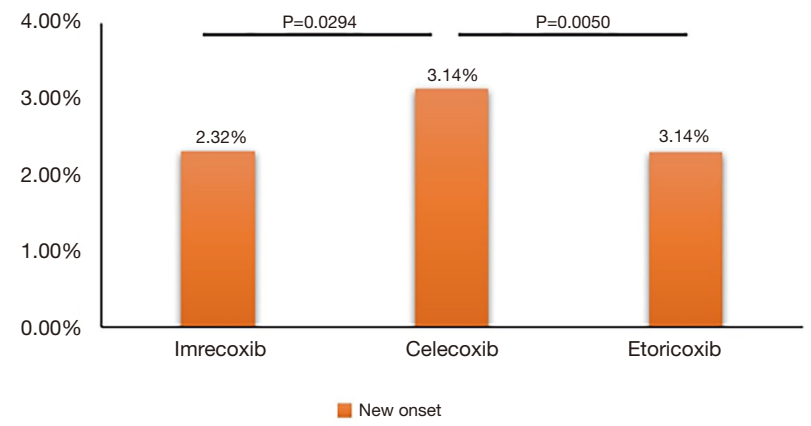

B

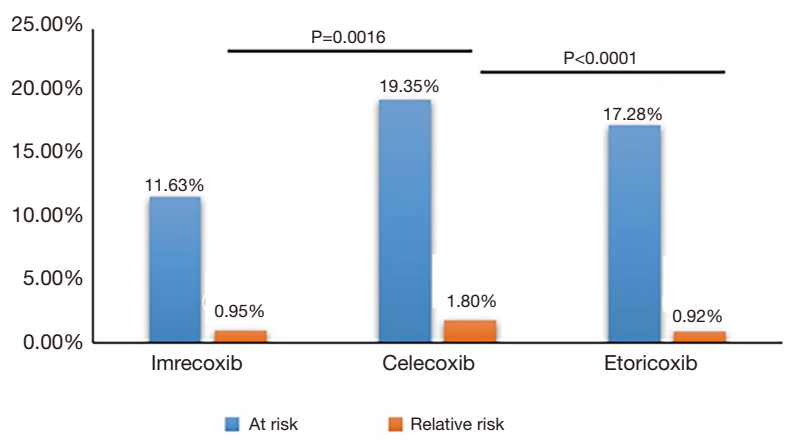

Figure 4 Occurrences of gastrointestinal complications, cardiovascular events and hypertension new-onset in patients at risk or relative risk after using different selective COX-2 inhibitors. (A) Gastrointestinal complications; (B) cardiovascular events; (C) hypertension new-onset. COX, cyclooxygenase.

into the numbers and characteristics of patients prescribed oral NSAIDs, including selective COX-2 inhibitors (i.e., imrecoxib, celecoxib, and etoricoxib), traditional NSAIDs (i.e., ibuprofen, diclofenac sodium, indometacin and acetaminophen), and combination NSAID prescriptions. The results also revealed the prescription patterns of oral NSAIDs, and the safety profiles of patients treated with different types of NSAIDs.

\section{Patients characteristics}

\section{Age}

In general, the results showed that NSAIDs were prescribed to patients of all age groups. Patients treated with selective COX-2 inhibitors were older than those treated with traditional NSAIDs (52.7 vs. 35.7 years). There may be two reasons. On the one hand, the elderly tend to gather many gastrointestinal risk factors (14), such as advanced age, history of peptic ulcers, and combined medications; on the other hand, selective COX-2 inhibitors have significant gastrointestinal safety compared to traditional NSAIDs (15). Therefore, clinicians are more inclined to prescribe selective COX-2 inhibitors for elderly patients. Notably, nearly half of the patients in this study who were prescribed were NSAIDs were aged over 45. However, somewhat surprisingly, $13.93 \%$ of the participants who were prescribed oral NSAIDs were children and adolescents (aged under 18). Presently, pharmacological research indicates that the use of oral NSAIDs, especially the three selective COX-2 inhibitors examined in this study, to treat children is rare. Indeed, the instructions for imrecoxib, celecoxib and etoricoxib clearly state that the safety and efficacy for children's use of these drugs have not yet been verified. Notably, traditional NSAIDs (mainly ibuprofen and paracetamol) have been reported to cause adverse events in children, including hypersensitivity reactions $(11,12)$. Appropriate drug provocation tests could be administered to determine whether one or more COX-2 specific or COX-2 preferential medications are safe for use $(16,17)$. However, the prescription of oral NSAIDs (regardless of whether they 
are selective COX-2 inhibitors or traditional NSAIDs) to children and adolescents should be carefully evaluated and drug instructions carefully considered.

\section{Type and frequency}

In relation to the frequency and type of NSAID prescribed, over $80 \%$ of the patients were prescribed an NSAID only once, and fewer than $10 \%$ of the patients were prescribed more than one type of NSAID. The results in this respect were similar among patients prescribed selective COX2 inhibitors and those prescribed traditional NSAIDs. In relation to NSAID combinations, patients were most commonly prescribed acetaminophen and ibuprofen (720 person-time). Thus, the results suggest that in clinical applications, courses of NSAIDs are relatively short, and combined NSAID prescriptions are not common. It may be that the duration of NSAID treatments is connected to the type of disease. For example, patients suffering from fever and acute pain were generally only treated with selective COX-2 inhibitors or traditional NSAIDs for a few days (18-20). Conversely, the courses of oral NSAID prescriptions for patients suffering from chronic pain and inflammation were more prolonged. Notably, the recommended course of treatment for selective COX2 inhibitors is usually 6-8 weeks. However, a course of treatment may take as long as 3-6 months to treat prophylaxis of attacks of acute gout (21), and a course of oral NSAIDs usually takes 2-4 weeks to treat hand osteoarthritis (22). The present study's findings in relation to the low frequency with which NSAIDs were prescribed were consistent with the data on which diseases were being treated. However, it should be noted that the results indicating that NSAIDs were only prescribed with low frequency could be related to the short follow-up time. The study's findings in relation to the appropriateness with which physicians prescribed oral NSAIDs is noteworthy.

\section{Prescription patterns}

\section{Departments and diseases}

The research showed that the departments using NSAIDs and the diseases treated by NSAIDs were very diverse. Traditional NSAIDs were most commonly used in emergency departments, while selective COX-2 inhibitors were most commonly used in orthopedic departments. Additionally, the most common diseases of patients prescribed both types of NSAIDs largely accorded with the results for the hospital departments. Selective COX-
2 inhibitors were most frequently prescribed to patients with osteoarthritis, while traditional NSAIDs were most frequently prescribed to patients with fevers. Selective COX-2 inhibitors, such as celecoxib and imrecoxib, are effective at managing pain in patients with knee osteoarthritis, and are routinely used in clinical practice (23-25). Compared to the courses of medication prescribed by the emergency department, those prescribed by orthopedic departments were relatively long, which may be one of the reasons why selective COX-2 inhibitors with fewer adverse GI effects were prescribed.

\section{Concomitant medications}

Most studies that include subgroup analyses of different anti-hypertensive regimens report that an increase in blood pressure (BP) (especially systolic BP) following the administration of a NSAID is more pronounced among patients who are treated with an ACEI or angiotensin receptor blocker (ARB) than other agents (26-29). Notably, in a nested case-control study of 78,379 patients, the absolute increase in acute kidney injury risk was higher when NSAIDs were used with diuretic agents and an ACEI or ARB than when NSAIDs were used with an ACEI or ARB alone (and no diuretic agents) (30). The results of the present study showed that $441(0.87 \%)$ patients took concomitant medications of ACEI plus diuretics if NSAIDs were prescribed, which is somewhat controversial given the guidelines (10). Given the possible GI complications NSAIDs can induce, it is recommended that patients with a moderate risk of peptic ulcer disease be prescribed a traditional NSAID plus a PPI or selective COX-2 inhibitor. It is also recommended that patients at high risk of peptic ulcer disease be prescribed a selective COX-2 inhibitor plus a PPI (10). Notably, the results of the present showed that only $25.49 \%$ of patients at risk of GI were prescribed NSAIDs plus PPIs. Given the number of reports of concomitant medicines being inappropriately prescribed under the guidelines, increased efforts need to be made to ensure the safe prescribing of oral NSAIDs.

\section{Safety}

Oral NSAIDs are the predominant medications used to manage fever, inflammation and pain worldwide; however, their safety, particularly in relation to patients at risk of $\mathrm{CV}$ events and GI complications, has raised concerns in recent years. This study sought to evaluate the factors of NSAIDs that induce adverse effects among high-risk populations. 


\section{Selective COX-2 inhibitors and traditional NSAIDs}

The findings revealed that in relation to GI complications and $\mathrm{CV}$ events, selective COX-2 inhibitors had a better safety profile than traditional NSAIDs no matter the population or the relative risks. Similar results were found in relation to new-onset hypertension. Our findings are supported by several other studies. Notably, selective COX2 inhibitors have been found to produce fewer upper GI ulcers and bleeds (31-33), and less GI upset (34) than traditional NSAIDs. It has been postulated that COX-2 inhibitors have a higher $\mathrm{CV}$ risk than traditional NSAIDs; however, the excess risk appears to be largely confined to rofecoxib $(35,36)$. The risk of $\mathrm{CV}$ disease following NSAID therapy is considerable in patients at high risk of $\mathrm{CV}(37,38)$ or those with a pre-existing $\mathrm{CV}$ disease $(38,39)$. In patients with a history of atherosclerotic $\mathrm{CV}$ events, a randomized controlled trial showed that the risk of a $\mathrm{CV}$ event after NSAID therapy for 18 months was $4.4-5.5 \%$ (40). Thus, appropriate recognition of high- risk cases, selection of a specific agent, choice of ulcer prophylaxis and monitoring after therapy are necessary to minimise the risk of adverse events (10).

\section{Different selective COX-2 inhibitors}

In relation to selective COX-2 inhibitors, the proportions of patients that suffered from GI complication, CV events or new-onset hypertension were relatively lower in patients treated with imrecoxib than in those treated with celecoxib and etoricoxib. Previous studies on the adverse effects of celecoxib and etoricoxib have shown that etoricoxib causes a greater increase in BP than celecoxib (and that the effects of celecoxib are relatively small) $(26,41,42)$. Research has also shown that celecoxib does not lead to an increase in the risk of CV events (43). The results of the present study also suggest that imrecoxib causes fewer adverse events than celecoxib and etoricoxib. Imrecoxib is a new selective COX-2 inhibitor that was developed to have moderate inhibition effects (44). Clinical trials have demonstrated that imrecoxib shows $50 \%$ inhibitory concentration $\left(\mathrm{IC}_{50}\right)$ of COX -1 and COX-2 isozymes by $115 \pm 28$ and $18 \pm 4 \mathrm{nmol} / \mathrm{L}$, respectively (45). Its selective index $\left(\mathrm{IC}_{50}, \mathrm{COX}_{-1 / \mathrm{COX} 2}\right)$ of 6.39 fell between that of meloxicam and celecoxib (46). It is currently registered in China for the symptomatic treatment of osteoarthritis, and has been widely prescribed since its launch in 2011 (45). Given its efficacy and that it causes less adverse events than celecoxib and etoricoxib, it has strong potential for applications in clinical scenarios.

\section{Limitations}

Due to a number of limitations, the findings of the present study should be interpreted cautiously. First, this study examined three centers that were all located in the Shandong province. Patients' information from a period of 8 years was evaluated; however, the sample size was still relatively narrow. Thus, the results may not be fully generalizable to other areas in east China. Future studies should be conducted in other cities and towns across China to address this limitation. Second, the number of patients who participated in the study may have been under- or over-estimated, as not all of the diagnostic information in Chinese HISs has been coded according to the International Classification of Diseases standards. Consequently, there may have been limitations in defining different diseases and analyzing the diagnosis information of patients who had been prescribed NSAIDs. Third, the duration of the follow-up period was not long due to the general weakness of the retrospective searches. Fourth, there are several shortcomings in retrospective research, such as selection bias and information bias, and the data that can be analyzed are limited. In the future, well-designed cohort studies or before-after studies should be undertaken to assess the adverse effects of oral NSAIDs, such as liver and kidney damage, after long periods among larger cohorts.

\section{Conclusions}

This clinical study used 8-year prescription databases of three Chinese hospitals to examine the prescription patterns of oral NSAIDs. The results showed that that NSAIDs were prescribed to patients of all ages and prescribed at a high rate to elderly patients. Traditional NSAIDs were most commonly used in emergency departments to treat fevers, while selective COX-2 inhibitors were most commonly used in orthopedic departments. The study also found that the occurrence of adverse events, including GI complications, CV events and new-onset hypertension, in high-risk populations could related to the use of both traditional NSAIDs and selective COX-2 inhibitors, and that selective COX-2 inhibitors might be safer than traditional NSAIDs. Further, some drugs, such as ACEI, were found to aggravate adverse events when prescribed in combination with oral NSAIDs. Further research should be conducted to assist in the standardization of clinical prescriptions of NSAIDs. 


\section{Acknowledgments}

Funding: None.

\section{Footnote}

Reporting Checklist: The authors have completed the STROBE reporting checklist. Available at http://dx.doi. org/10.21037/apm-20-2356

Data Sharing Statement: Available at http://dx.doi. org/10.21037/apm-20-2356

Conflicts of Interest: All authors have completed the ICMJE uniform disclosure form (available at http://dx.doi. org/10.21037/apm-20-2356). The authors have no conflicts of interest to declare.

Ethical Statement: The authors are accountable for all aspects of the work in ensuring that questions related to the accuracy or integrity of any part of the work are appropriately investigated and resolved. This study conformed to the standards of the Declaration of Helsinki (as revised in 2013) and current ethical guidelines and was reviewed and approved by the Institutional Review Board of the Third People's Hospital of Jinan (No. 2020-sy005). The need for informed consent was waived by the Institutional Review Board.

Open Access Statement: This is an Open Access article distributed in accordance with the Creative Commons Attribution-NonCommercial-NoDerivs 4.0 International License (CC BY-NC-ND 4.0), which permits the noncommercial replication and distribution of the article with the strict proviso that no changes or edits are made and the original work is properly cited (including links to both the formal publication through the relevant DOI and the license). See: https://creativecommons.org/licenses/by-nc-nd/4.0/.

\section{References}

1. Mizushima T. Molecular Mechanism for Various Pharmacological Activities of NSAIDS. Pharmaceuticals (Basel) 2010;3:1614-36.

2. Mitchell JA, Warner TD. Cyclo-oxygenase-2: pharmacology, physiology, biochemistry and relevance to NSAID therapy. Br J Pharmacol 1999;128:1121-32.

3. Braun J, van den Berg R, Baraliakos X, et al. 2010 update of the ASAS/EULAR recommendations for the management of ankylosing spondylitis. Ann Rheum Dis 2011;70:896-904.

4. Zhang W, Doherty M, Arden N, et al. EULAR evidence based recommendations for the management of hip osteoarthritis: report of a task force of the EULAR Standing Committee for International Clinical Studies Including Therapeutics (ESCISIT). Ann Rheum Dis 2005;64:669-81.

5. Richette P, Doherty M, Pascual E, et al. 2016 updated EULAR evidence-based recommendations for the management of gout. Ann Rheum Dis 2017;76:29-42.

6. Dahl JB, Nielsen RV, Wetterslev J, et al. Post-operative analgesic effects of paracetamol, NSAIDs, glucocorticoids, gabapentinoids and their combinations: a topical review. Acta Anaesthesiol Scand 2014;58:1165-81.

7. Enthoven WT, Roelofs PD, Deyo RA, van Tulder MW, Koes BW. Non-steroidal anti-inflammatory drugs for chronic low back pain. Cochrane Database Syst Rev 2016;2:CD012087.

8. Machado GC, Maher CG, Ferreira PH, et al. Nonsteroidal anti-inflammatory drugs for spinal pain: a systematic review and meta-analysis. Ann Rheum Dis 2017;76:1269-78.

9. Vonkeman HE, van de Laar MA. Nonsteroidal antiinflammatory drugs: adverse effects and their prevention. Semin Arthritis Rheum 2010;39:294-312.

10. Szeto CC, Sugano K, Wang JG, et al. Non-steroidal antiinflammatory drug (NSAID) therapy in patients with hypertension, cardiovascular, renal or gastrointestinal comorbidities: joint APAGE/APLAR/APSDE/APSH/ APSN/PoA recommendations. Gut 2020;69:617-29.

11. Kidon M, Blanca-Lopez N, Gomes E, et al. EAACI/ ENDA Position Paper: Diagnosis and management of hypersensitivity reactions to non-steroidal antiinflammatory drugs (NSAIDs) in children and adolescents. Pediatr Allergy Immunol 2018;29:469-80.

12. Mori F, Atanaskovic-Markovic M, Blanca-Lopez N, et al. A Multicenter Retrospective Study on Hypersensitivity Reactions to Nonsteroidal Anti-Inflammatory Drugs (NSAIDs) in Children: A Report from the European Network on Drug Allergy (ENDA) Group. J Allergy Clin Immunol Pract 2020;8:1022-31.

13. Abraham NS, Hlatky MA, Antman EM, et al. ACCF/ ACG/AHA 2010 expert consensus document on the concomitant use of proton pump inhibitors and thienopyridines: a focused update of the ACCF/ACG/ AHA 2008 expert consensus document on reducing the 
gastrointestinal risks of antiplatelet therapy and NSAID use. Am J Gastroenterol 2010;105:2533-49.

14. García Rodríguez LA, Jick H. Risk of upper gastrointestinal bleeding and perforation associated with individual non-steroidal anti-inflammatory drugs. Lancet 1994;343:769-72.

15. Moore RA, Derry S, Phillips CJ, McQuay HJ. Nonsteroidal anti-inflammatory drugs (NSAIDs), cyxlooxygenase-2 selective inhibitors (coxibs) and gastrointestinal harm: review of clinical trials and clinical practice. BMC Musculoskelet Disord 2006;7:79.

16. Sánchez-Borges M, Caballero-Fonseca F, Capriles-Hulett A. Tolerance of nonsteroidal antiinflammatory drugsensitive patients to the highly specific cyclooxygenase 2 inhibitors rofecoxib and valdecoxib. Ann Allergy Asthma Immunol 2005;94:34-38.

17. Loh W, Lim HH, Rao R, et al. Tolerance to etoricoxib in children with nonsteroidal anti-inflammatory drug hypersensitivity. Asia Pac Allergy 2015;5:40-6.

18. Schachtel BP, McCabe D, Berger M, et al. Efficacy of low-dose celecoxib in patients with acute pain. J Pain 2011;12:756-63.

19. Onda A, Ogoshi A, Itoh M, et al. Comparison of the effects of treatment with celecoxib, loxoprofen, and acetaminophen on postoperative acute pain after arthroscopic knee surgery: A randomized, parallel-group trial. J Orthop Sci 2016;21:172-7.

20. Crook J. Fever management: evaluating the use of ibuprofen and paracetamol. Paediatr Nurs 2010;22:22-6.

21. Khanna D, Khanna PP, Fitzgerald JD, et al. 2012 American College of Rheumatology guidelines for management of gout. Part 2: therapy and antiinflammatory prophylaxis of acute gouty arthritis. Arthritis Care Res (Hoboken) 2012;64:1447-61.

22. Kroon FPB, Carmona L, Schoones JW, et al. Efficacy and safety of non-pharmacological, pharmacological and surgical treatment for hand osteoarthritis: a systematic literature review informing the 2018 update of the EULAR recommendations for the management of hand osteoarthritis. RMD Open 2018;4:e000734.

23. Xu C, Gu K, Yasen Y, et al. Efficacy and Safety of Celecoxib Therapy in Osteoarthritis: A Meta-Analysis of Randomized Controlled Trials. Medicine (Baltimore) 2016;95:e3585.

24. Puljak L, Marin A, Vrdoljak D, et al. Celecoxib for osteoarthritis. Cochrane Database Syst Rev 2017;5:CD009865.

25. Chen JH, Wu GH, Deng S. The efficacy of imrecoxib in patients with retrogressive knee arthritis. Chinese Journal of Clinical Rational Drug Use 2006;9:38-9.

26. Aljadhey $\mathrm{H}, \mathrm{Tu} \mathrm{W}$, Hansen RA, et al. Comparative effects of non- steroidal anti- inflammatory drugs (NSAIDs) on blood pressure in patients with hypertension. BMC Cardiovasc Disord 2012;12:93.

27. Ishiguro C, Fujita T, Omori T, et al. Assessing the effects of non- steroidal anti- inflammatory drugs on antihypertensive drug therapy using post- marketing surveillance database. J Epidemiol 2008;18:119-24.

28. Whelton A, White WB, Bello AE, et al. Effects of celecoxib and rofecoxib on blood pressure and edema in patients $\geq 65$ years of age with systemic hypertension and osteoarthritis. Am J Cardiol 2002;90:959-63.

29. Pavlicević I, Kuzmanić M, Rumboldt M, et al. Interaction between antihypertensives and NSAIDs in primary care: a controlled trial. Can J Clin Pharmacol 2008;15:e372-82.

30. Dreischulte T, Morales DR, Bell S, et al. Combined use of nonsteroidal anti- inflammatory drugs with diuretics and/ or renin-angiotensin system inhibitors in the community increases the risk of acute kidney injury. Kidney Int 2015;88:396-403.

31. Silverstein FE, Faich G, Goldstein JL, et al. Gastrointestinal toxicity with celecoxib vs nonsteroidal anti-inflammatory drugs for osteoarthritis and rheumatoid arthritis: the CLASS study: a randomized controlled trial. Celecoxib Long-term Arthritis Safety Study. JAMA 2000;284:1247-55.

32. Mamdani M, Rochon PA, Juurlink DN, et al. Observational study of upper gastrointestinal haemorrhage in elderly patients given selective cyclo-oxygenase-2 inhibitors or conventional non-steroidal anti-inflammatory drugs. BMJ 2002;325:624-9.

33. Nørgård B, Pedersen L, Johnsen SP, et al. COX-2-selective inhibitors and the risk of upper gastrointestinal bleeding in high-risk patients with previous gastrointestinal diseases: a population-based case-control study. Aliment Pharmacol Ther 2004;19:817-25.

34. Arboleya LR, de la Figuera E, Soledad Garcia M, et al. Experience of rofecoxib in patients with osteoarthritis previously treated with traditional non-steroidal antiinflammatory drugs in Spain: results of phase 2 of the VICOXX study. Curr Med Res Opin 2003;19:288-97.

35. Bombardier C, Laine L, Reicin A, et al. Comparison of upper gastrointestinal toxicity of rofecoxib and naproxen in patients with rheumatoid arthritis. $\mathrm{N}$ Engl J Med 2000;343:1520-8.

36. McGettigan P, Henry D. Cardiovascular risk and 
inhibition of cyclooxygenase: a systematic review of the observational studies of selective and nonselective inhibitors of cyclooxygenase 2. JAMA 2006;296:1633-44.

37. Solomon DH, Glynn RJ, Rothman KJ, et al. Subgroup analyses to determine cardiovascular risk associated with nonsteroidal antiinflammatory drugs and coxibs in specific patient groups. Arthritis Rheum 2008;59:1097-104.

38. Bhala N, Emberson J, Merhi A, et al. Vascular and upper gastrointestinal effects of non- steroidal anti- inflammatory drugs: meta- analyses of individual participant data from randomised trials. Lancet 2013;382:769-79.

39. Schjerning Olsen AM, Gislason GH, McGettigan P, et al. Association of NSAID use with risk of bleeding and cardiovascular events in patients receiving antithrombotic therapy after myocardial infarction. JAMA 2015;313:805-14.

40. Chan FKL, Ching JYL, Tse YK, et al. Gastrointestinal safety of celecoxib versus naproxen in patients with cardiothrombotic diseases and arthritis after upper gastrointestinal bleeding (concern): an industryindependent, double- blind, double- dummy, randomised trial. Lancet 2017;389:2375-82.

41. Ruschitzka F, Borer JS, Krum H, et al. Differential blood pressure effects of ibuprofen, naproxen, and celecoxib in patients with arthritis: the PRECISION- ABPM

Cite this article as: Meng Q, Zhang Z, Li F, Li J, Wang N, Guo Z, Wang J, Ye X, Li Y. The prescription patterns and safety profiles of oral non-steroidal anti-inflammatory drugs in China: an 8-year real-life analysis. Ann Palliat Med 2021;10(2):2224-2237. doi: 10.21037/apm-20-2356 (prospective randomized evaluation of celecoxib integrated safety versus ibuprofen or naproxen ambulatory blood pressure measurement) trial. Eur Heart J 2017;38:3282-92.

42. Chan CC, Reid CM, Aw TJ, et al. Do COX-2 inhibitors raise blood pressure more than nonselective NSAIDs and placebo? An updated meta- analysis. J Hypertens 2009;27:2332-41.

43. Moore RA, Derry S, Makinson GT, et al. Tolerability and adverse events in clinical trials of celecoxib in osteoarthritis and rheumatoid arthritis: systematic review and metaanalysis of information from company clinical trial reports. Arthritis Res Ther 2005;7:R644-65.

44. Zuo CZ, Gong Y, Hou XY, et al. Effect of Fluconazole on the Pharmacokinetic Properties of Imrecoxib, a Novel NSAID: A Single-center, Open-label, Self-controlled Study in Healthy Chinese Male Volunteers. Clin Ther 2018;40:1347-56.

45. Feng Z, Chu F, Guo Z, et al. Synthesis and antiinflammatory activity of the major metabolites of imrecoxib. Bioorg Med Chem Lett 2009;19:2270-2.

46. Tacconelli S, Capone ML, Patrignani P. Clinical pharmacology of novel selective COX-2 inhibitors. Curr Pharm Des 2004;10:589-601.

(English Language Editor: L. Huleatt) 


\section{Supplementary}

Table S1 NSAIDs combination prescriptions during each visit (person-time)

\begin{tabular}{|c|c|}
\hline NSAIDs combination & $\begin{array}{c}\text { Person- } \\
\text { time }\end{array}$ \\
\hline Acetaminophen + ibuprofen & 720 \\
\hline Diclofenac sodium + indometacin & 386 \\
\hline Diclofenac sodium + ibuprofen & 276 \\
\hline Acetaminophen + indometacin & 191 \\
\hline Indometacin + ibuprofen & 152 \\
\hline Diclofenac sodium + acetaminophen & 121 \\
\hline Diclofenac sodium + celecoxib & 113 \\
\hline Etoricoxib + celecoxib & 66 \\
\hline Etoricoxib + diclofenac sodium & 46 \\
\hline Indometacin + celecoxib & 32 \\
\hline Diclofenac sodium + loxoprofen & 31 \\
\hline Celecoxib + acetaminophen & 28 \\
\hline Diclofenac sodium + imrecoxib & 26 \\
\hline Celecoxib + ibuprofen & 22 \\
\hline Etoricoxib + ibuprofen & 17 \\
\hline Etoricoxib + indometacin & 14 \\
\hline Indometacin + loxoprofen & 12 \\
\hline Diclofenac sodium + indometacin + acetaminophen & 11 \\
\hline Acetaminophen + loxoprofen & 10 \\
\hline Diclofenac sodium + indometacin + ibuprofen & 9 \\
\hline Celecoxib + loxoprofen & 9 \\
\hline Celecoxib + imrecoxib & 9 \\
\hline Etoricoxib + loxoprofen & 7 \\
\hline Etoricoxib + imrecoxib & 7 \\
\hline Acetaminophen + imrecoxib & 6 \\
\hline Etoricoxib + diclofenac sodium + indometacin & 4 \\
\hline Etoricoxib + acetaminophen & 4 \\
\hline Diclofenac sodium + celecoxib + acetaminophen & 4 \\
\hline Diclofenac sodium + acetaminophen + ibuprofen & 3 \\
\hline Indometacin + imrecoxib & 3 \\
\hline Etoricoxib + diclofenac sodium + celecoxib & 2 \\
\hline Diclofenac sodium + indometacin + celecoxib & 2 \\
\hline Diclofenac sodium + celecoxib + ibuprofen & 2 \\
\hline
\end{tabular}

Table S1 (continued)
Table S1 (continued)

\begin{tabular}{lc}
\hline NSAIDs combination & $\begin{array}{c}\text { Person- } \\
\text { time }\end{array}$ \\
\hline Indometacin + acetaminophen + ibuprofen & 2 \\
Ibuprofen + loxoprofen & 2 \\
Ibuprofen + imrecoxib & 2 \\
Loxoprofen + imrecoxib & 2 \\
Etoricoxib + celecoxib + imrecoxib & 1 \\
Diclofenac sodium + indometacin + loxoprofen & 1 \\
Diclofenac sodium + celecoxib + loxoprofen & 1 \\
Diclofenac sodium + celecoxib + imrecoxib & 1 \\
Indometacin + celecoxib + ibuprofen + imrecoxib & 1 \\
Indometacin + ibuprofen + loxoprofen & 1 \\
Indometacin + ibuprofen + imrecoxib & 1 \\
Total & 2,360 \\
\hline
\end{tabular}

NSAIDs, non-steroidal antiinflammatory drugs. 